\title{
Nationwide Survey of German Outpatient Gynecologic Oncology Practices during the Coronavirus Disease 2019 Pandemic: Reactions to the First Wave and Future Perspectives
}

\author{
Erwin $\mathrm{Vu}^{\mathrm{a}} \quad$ Christina Schröder $^{\mathrm{b}} \quad$ Jonas Dülk $^{\mathrm{c}} \quad$ Jean-Jacques Stelmes $^{\mathrm{d}}$ \\ Jennifer $\mathrm{Vu}^{\mathrm{c}}$ Jörg Schilling ${ }^{\mathrm{e}}$ Frank Gerhard Förster ${ }^{\mathrm{f}, \mathrm{g}}$ Robert Förster ${ }^{\mathrm{b}, \mathrm{h}}$ \\ Berufsverband Niedergelassener Gynäkologischer Onkologen in \\ Deutschland e.V. \\ aDepartment of Radiation Oncology, Cantonal Hospital St. Gallen, St. Gallen, Switzerland; 'blnstitute for Radiation \\ Oncology, Cantonal Hospital Winterthur, Winterthur, Switzerland; ${ }^{\circ}$ Friedrich Alexander University Erlangen,

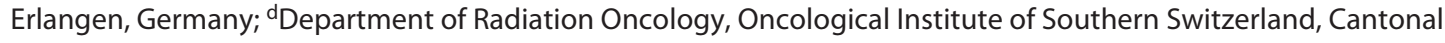 \\ Hospitals, Bellinzona, Switzerland; ' Gemeinschaftspraxis Dres. med. Schilling, Till and Kohn, Berlin, Germany; \\ ${ }^{f}$ MVZ Flemmingstraße, Poliklinik GmbH, Chemnitz, Germany; 'Faculty of Business and Economics, University of

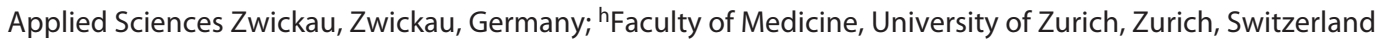

\section{Keywords}

Coronavirus disease 2019 - Pandemic · First wave ·

Gynecologic oncology · Patient care

\begin{abstract}
Introduction: In the spring of 2020, coronavirus disease 2019 posed a substantial challenge for countries and their healthcare systems. In Germany, over $70 \%$ of all cancer patients are treated in an outpatient setting, so gynecologic oncology practices are the guarantors of optimal patient care. We developed a survey to evaluate the management of gynecologic oncology patients. Methods: The survey consisted of 38 questions and was sent to the members of the Berufsverband Niedergelassener Gynäkologischer Onkologen in Deutschland e.V. (BNGO), a professional association of gynecologic oncologists in the outpatient sector in Germany. Results: The survey was completed by 54 out of 133 (41\%) gynecologic oncologists from 14 out of 15 (93\%) federal states where the BNGO is represented. Facing the pandemic, popular measures were mask requirements (100\%), restriction of access to practices (94\%), increased number of disinfectant dispensers (85\%), installment of panes of acrylic
\end{abstract}

karger@karger.com www.karger.com/brc

Karger $\frac{1}{\%}$

BOPEN ACCESS (c) 2021 The Author(s)

Published by S. Karger AG, Basel

This is an Open Access article licensed under the Creative Common Attribution-NonCommercial-4.0 International License (CC BY-NC) (http://www.karger.com/Services/OpenAccessLicense), applicable to the online version of the article only. Usage and distribution for commercial purposes requires written permission. glass $(76 \%)$, or spatial alterations (67\%). For most patients the pandemic had no influence on prioritization of therapies $(82 \%)$ or prescribed systemic treatments $(87 \%)$. Despite an increase in perceived psychological burden among the staff (72\%), 85\% (45/54) of the practices were not offered any additional psychological support. Discussion and Conclusion: As most cancer patients in Germany are treated in an outpatient setting, a suitable reaction of oncology centers to the new circumstances was crucial to secure optimal treatment and patient care. Nevertheless, the low prioritization of mental health or distress of healthcare workers poses a serious threat to the maintenance of optimal medical care in further waves of the pandemic.

(c) 2021 The Author(s) Published by S. Karger AG, Basel

\section{Introduction}

In 2020, a new virus had a big influence on healthcare worldwide. Since the first infections of severe acute respiratory syndrome coronavirus 2 in November 2019 [1], the virus rapidly spread all over the world and the 
Fig. 1. Sources of information during the first wave of the COVID-19 pandemic. COVID-19, coronavirus disease 2019.

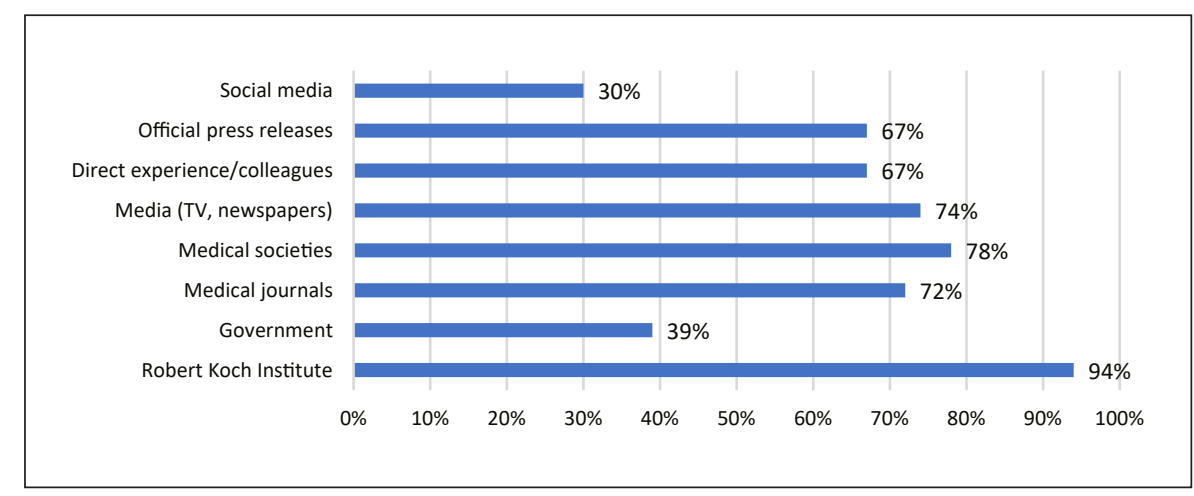

disease caused by the virus was later on named coronavirus disease 2019 (COVID-19) [2]. Due to the pandemic, many medical societies published updates of their guidelines [3-6]. However, especially during the first wave of infection in the spring of 2020, the novel virus posed a substantial challenge for countries and their healthcare systems [7]. While Asian countries had faced several epidemics (severe acute respiratory syndrome, Middle East respiratory syndrome) in the last decades and had learned from these experiences [8-10], COVID-19 hit European countries completely unprepared. One of the main issues was ensuring the availability of medical services in times of limited resources and social distancing [11]. Therefore, medical care had to be rethought and new services, e.g., consultations via telephone or virtual meetings, were introduced [12]. While elective treatments were often postponed $[13,14]$, this was not possible in oncology because the continuation of treatment is crucial for cancer patients [15]. As interruptions of treatment regimens are associated with decreasing survival and insufficient tumor or symptom control [16], several medical societies issued guidelines and recommendations, e.g., for the prioritization of patients in a setting of compromised resources [17]. The same occurred for gynecologic oncology patients. The European Society of Gynecologic Oncology (ESGO) and the Society of Gynecologic Oncology (SGO) updated several guidelines [18] and recommendations. In Germany, over $70 \%$ of all cancer patients are treated in an outpatient setting [19], so gynecologic oncology practices are the guarantors of optimal patient care.

Facing the COVID-19 pandemic, we developed a survey to evaluate the management of gynecologic oncology patients and adaptions in the daily workflows of gynecologic oncology practices. The survey was sent to the members of the Berufsverband Niedergelassener Gynäkologischer Onkologen in Deutschland e.V. (BNGO), which is a professional association of gynecologic oncologists practicing in the outpatient sector in Germany.
Table 1. Respondent characteristics

Value

BNGO characteristics

Responding members

Represented states

$54 / 133(41 \%)$

$14 / 15(93.3 \%)$

Tumor patients per annual quarter

331 (range, 40-950)

\section{Organization characteristics}

Single practice

$39 \%(21 / 54)$

Group practice

Local hospital

$48 \%(26 / 54)$

Tumor patients per annual quarter

Financial loss expected

$9 \%(5 / 54)$

331 (range, 40-950)

$81 \%$ yes

Expected average financial loss

\section{Methods}

The BNGO is a society of 133 gynecologic oncologists practicing in 15 German federal states with a focus on quality control and scientific exchange. While 39\% (21/54) of the participants were working in their own private practice, over $48 \%(26 / 54)$ were organized in a group practice. Only a minority of $9 \%(5 / 54)$ of centers were affiliated with a local hospital. While most BNGO members regularly see general gynecologic patients and pregnant women, the majority specialize in the systemic treatment of breast and gynecologic cancers. Therefore, most cancer diagnoses are made externally and patients typically are then referred from collaborating hospitals and general gynecologists or come as self-referrals for oncologic treatment to the BNGO practices. Details on the BNGO and its members are shown in Table 1.

The survey consisted of 38 questions (see online suppl. material, www.karger.com/doi/10.1159/000518858) and was created as an online survey with SurveyMonkey (SurveyMonkey Inc., San Mateo, CA, USA) in April 2020. The questionnaire focused on the impact of COVID-19 on changes of workflows and patient management. Furthermore, the questions intended to assess whether there was a perceived impact of the pandemic and the modified work environment on the mental health of healthcare workers. After approval by the BNGO board, the link to the online survey was sent via email to all BNGO members by the end of May 2020. All statistics and figures were generated with Excel version 2016 (Microsoft Corp., Redmond, WA, USA). 
Fig. 2. Direct contact partners for the

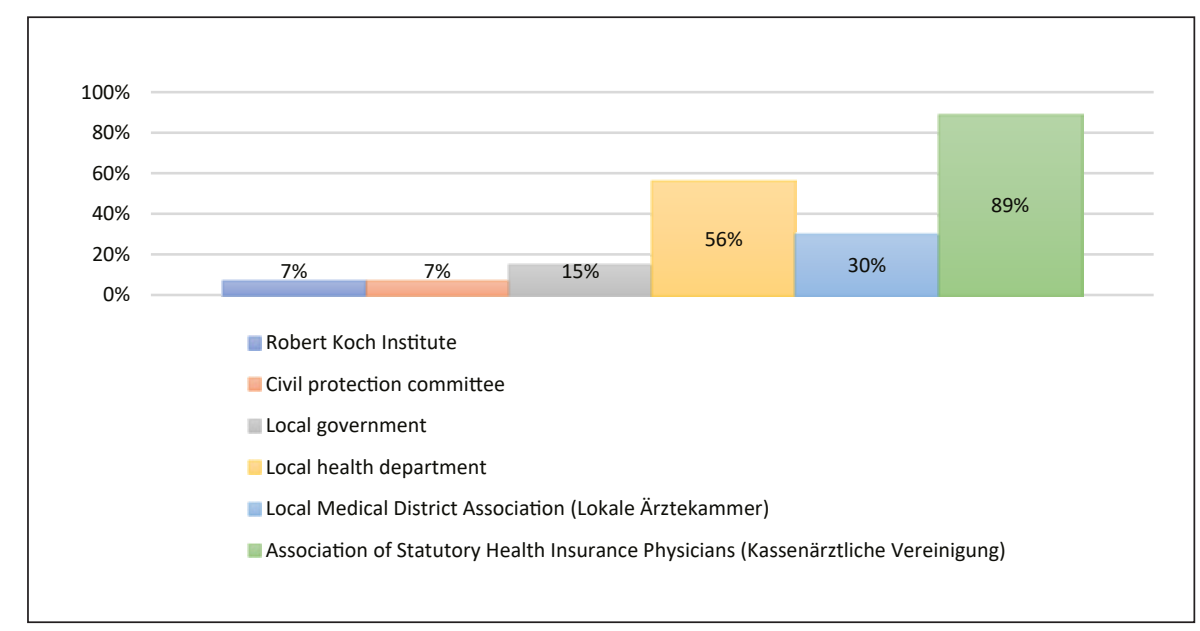
healthcare institutions.

\section{Results}

By May 29, 2020 the survey had been completed by 54 out of $133(41 \%)$ gynecologic oncologists from 14 out of 15 (93\%) German federal states where the BNGO is represented. During the first wave of the pandemic, information on the novel virus and its characteristics was rare. Regarding this, the most-sought sources of information are shown in Figure 1. With over 94\% (51/54), the most frequently mentioned source of information for the questioned gynecologic oncologists was the Robert Koch Institute, representing the highest federal authority for observation of diseases and elaborating scientific justification of measures to protect the population. With the daily update on the infection numbers in Germany, the Robert Koch Institute takes a prominent role in informing the German people during the pandemic. The demand for information to cope with a novel virus can be seen in the high relevance of medical societies $(78 \%, 42 / 54)$ and journals $(72 \%$, $39 / 54$ ) for our study cohort. This goes along with the massive increase in research articles, reviews, or editorials related to COVID-19 in 2020 [20].

The pandemic led to changes in workflows and working time models in 65\% (35/54) of practices. In accordance with general recommendations of the local governments and the German Ministry of Health, every institution introduced mask requirements (Table 2). Other popular measures taken were the restriction of access to practices in 51 out of 54 organizations (94\%), increasing the number of disinfectant dispensers (85\%), the installment of panes of acrylic glass (76\%), and spatial alterations in $67 \%(36 / 54)$ of practices. Due to distance rules, $33 \%(18 / 54)$ of the respondents introduced doctor consultations via video call for their patients. While over $81 \%$ $(44 / 54)$ noticed an increase of workload for their employees, $65 \%(35 / 54)$ also reported a substantial influence on their private life due to the exposition to COVID-19.
Table 2. Introduced hygienic actions

\begin{tabular}{ll}
\hline Hygienic action & $n(\%)$ \\
\hline Mask requirements & $54(100 \%)$ \\
Restricted access for relatives & $51(94 \%)$ \\
Additional disinfectant dispensers & $45(85 \%)$ \\
Panes of acrylic glass & $41(75 \%)$ \\
Spatial change in the practice & $36(67 \%)$ \\
Temperature measurements & $14(26 \%)$ \\
Consultations via video call & $18(33 \%)$ \\
Reduction of appointments & $24(44 \%)$ \\
\hline
\end{tabular}

Aid by the government (face masks, disinfectants, protective clothing, etc.) was offered to almost every organization $(53 / 54 ; 98 \%)$, although over $27 \%$ (15/54) of the respondents commented that the aid was offered too late. In addition, most consulted gynecologic oncologists (43/54) did not have a direct contact in the government to coordinate the reactions to the COVID-19 pandemic. While 30 respondents (56\%) were in exchange with their local Medical District Association (Ärztekammer), their local Association of Statutory Health Insurance Physicians (Kassenärztliche Vereinigung) contacted 89\% (48/54) of the inquired physicians (Fig. 2). Despite an increase in perceived psychological burden among the staff $(>72 \%, 39 / 54), 83 \%(45 / 54)$ of the practices were not offered any additional psychological support by any government body or professional association (Table 3 ). While over $72 \%(39 / 54)$ of institutions noticed an increase in private stress (e.g., childcare, home schooling, etc.) among the staff, there was no increase in sick days in most organizations $(51 / 54$; $94 \%)$. While only 28 of 54 responding gynecologic oncologists (52\%) were under the impression that the pandemic had led to further digitization in medicine, $70 \%(38 / 54)$ believed that digitization would generally be beneficial for their institution. 
Table 3. Effect of the COVID-19 pandemic on healthcare institutions and providers

\begin{tabular}{ll}
\hline Observed effects & $n(\%)$ \\
\hline Changes in workflows and working time models & $35(65 \%)$ \\
Changes of meeting forms & $51(94 \%)$ \\
Progression of digitalization & $28(52 \%)$ \\
Influence on the private life of the responsible doctors & $35(65 \%)$ \\
Increased workload for the healthcare workers & $44(81 \%)$ \\
Increased psychological burden for the healthcare workers & $39(72 \%)$ \\
Additional psychological support for the healthcare workers & $7(13 \%)$ \\
Increase in private stress (e.g., childcare) & $45(85 \%)$ \\
Increased sick days & $3(6 \%)$ \\
\hline
\end{tabular}

COVID-19, coronavirus disease 2019.
With a mean of 331 (range, 40-950) tumor patients per annual quarter, for most cancer patients the pandemic had no influence on prioritization of therapies (82\%), treatment schemes $(67 \%)$, or prescribed systemic treatments (87\%) (Table 4). Mostly, the increased use of granulocyte colony-stimulating factor was stated in the comment section of the survey as a change of treatment schema. Although $44 \%(24 / 54)$ of all participants reduced the number of appointments for their patients, many respondents commented that this was not done for cancer patients. Nevertheless, half of the responding doctors (50\%) reported that cancer patients had postponed or cancelled their scheduled appointments due to the pandemic (mainly aftercare examinations). However, a majority of $72 \%(39 / 54)$ of the respondents did not perceive a general deterioration of patient care.

Next to an impact on their private lives as an exposed risk group (65\%), 81\% (44/54) of the institutions expected a mean financial loss of $21 \%$ (range, $5-50 \%$ ) for the fiscal year 2020. This also corresponded with a perceived lack of support from the health insurance providers $(78 \%$, $42 / 54)$.

\section{Discussion}

This survey portrayed the reaction of gynecologic oncology practices in Germany during the first wave of the COVID-19 pandemic. Facing increasing infection counts, the German government announced the first lockdown for the German population in March 2020 [21]. On March 13, 2020 the German federal government announced a decree to postpone all unnecessary medical interventions and treatments, so that resources could be transferred to intensive care units whenever needed [22]. When the survey was sent out to the BNGO members in May 2020, first steps to reopen public life (hair salons, restaurants, bars, etc.) were taken by the federal government after 7 weeks of lockdown. Therefore, the answers of this survey represent the fresh impressions of the first complete lockdown
Table 4. Effect of the COVID-19 pandemic on patients

\begin{tabular}{ll}
\hline Observed effects & $n(\%)$ \\
\hline Reduced number of patients & $30(56 \%)$ \\
Modified prioritization of therapies & $9(17 \%)$ \\
Modification of treatment schemes & $18(33 \%)$ \\
Change of prescribed systemic therapies & $6(11 \%)$ \\
Postponed appointments & $27(50 \%)$ \\
Observed deterioration of patient care & $15(28 \%)$ \\
\hline
\end{tabular}

COVID-19, coronavirus disease 2019.

in Germany. This first wave of the COVID-19 pandemic was characterized by an unfamiliar situation of limited resources and great uncertainty. Therefore, many medical professional societies quickly released updated guidelines to support clinicians (the SGO, the British Gynecologic Oncology Society, etc.) [23].

As most cancer patients in Germany are treated in an outpatient setting [19], a suitable reaction of oncology centers to the new circumstances was crucial to secure optimal treatment and patient care. With over 3.5 million oncologic outpatient contacts per year, German healthcare providers were forced to quickly adapt to the new situation. Confronted with a highly infectious virus and not much solid information about the extent of the pandemic, especially oncologists faced the difficult task of guaranteeing a safe environment for patients and healthcare workers [24]. Due to the federalist organization of healthcare politics in Germany with different laws and different responsible state institutions, the communication and coordination of healthcare and cancer care in particular was extremely challenging during the first wave of the COVID-19 pandemic. Our survey provides a snapshot of the situation for gynecologic oncology practices in April 2020 and highlights the reactions to this unprecedented disruption of healthcare services. One of the main sources of support for the BNGO members were the local Medical District Associations (30\%, 16/54) and As- 
sociations of Statutory Health Insurance Physicians (89\%), providing evidence how well organized the medical profession is in Germany. These associations ensure that the outpatient medical care works frictionless and represent the political interests of outpatient healthcare providers. As our study demonstrates, the organizations are an important resource for doctors in dealing with this extraordinary health crisis.

The new circumstances were reported to lead to worsening of clinical outcomes, especially for cancer patients: in The Lancet Oncology, Tang and $\mathrm{Hu}$ [25] compared several studies and global statistics on patients with a cancer diagnosis and COVID-19 infection and concluded that patients with cancer have worse clinical outcomes of COVID-19 compared to patients without a cancer diagnosis. This observation was confirmed by other groups [26, 27] and underlines the special vulnerability and the importance of the goal to mitigate the risk of infection for cancer patients. In order to guarantee a safe environment for both patients and healthcare workers, reduction of in-person visits [28, 29] or the increase of telemedicine [30] were popular steps in healthcare delivery worldwide. This also applies to the reported reactions of the BNGO members, next to the previously mentioned measures (Table 2).

Two recently published analyses also emphasize the importance of seamless cancer care. Duffy et al. [31] examined the effect of regular mammography screening in a large population of over 500,000 women between 1992 and 2016. Thereby, the authors focused on the effect of the examinations on mortality from breast cancer and concluded that women who participated in regular mammography screenings had a $49 \%$ lower risk of breast cancer mortality and a 50\% lower risk of death from breast cancer. Interestingly, missing one of the last two examinations already correlated with a significantly higher risk of breast cancer death. These findings were confirmed in a retrospective analysis by Toss et al. [32]. They evaluated a 2-month screening interruption in Italy due to the COVID-19 pandemic. This stop of screening between May and July 2020 led to an increase in node-positive and stage III breast cancer. The authors recommended a quick restoration of the full capacity of breast cancer screening and adequate prioritization strategies.

A prospective registry of Frey et al. [33] demonstrated that more than $38 \%$ among 302 patients with gynecologic cancer had to experience a treatment delay of in- and/ or outpatient care or a change or cancellation during the first months of the pandemic (March to April 2020). These and other reports [34] showed the challenges for healthcare providers in gynecologic patient management during the first phase of the pandemic. Facing these challenges, experts tried to figure out reasonable standards of care and released statements to provide aid for gynecologists all over the world. For example, the SGO put on sev- eral webinars about the treatment of patients with gynecologic cancers in COVID-19-burdened regions. Uwins et al. [35] provided an overview of the updated guidelines for gynecologic cancers.

Our study illustrates how gynecologic oncologists in Germany coped with the new circumstances and introduced extended concepts of hygiene, such as mask requirement or an increased number of disinfectant dispensers. In order to guarantee optimal treatment, the prescribed systemic treatments mostly were not changed. Although these steps led to increased workload, increased psychological burden, and private stress for the staff, the oncology centers proved their efficiency and capacity to handle an exceptional health crisis to secure the well-being of their patients. This was accomplished at the expense of a drastic influence on the private lives of the oncologic staff. Other groups also described the same increase in distress: moral distress, personal challenges, or burnout [36, 37]. Our survey confirms the findings of other studies, which reported an increase in psychological burden of healthcare professionals in Germany [38] and internationally $[39,40]$. As this topic plays a subordinate role in the political discussion of European governments, only little to no efforts have been made to address the burden of healthcare workers. Therefore, Hlubocky et al. [41] published an editorial with recommendations for the implementation of evidence-based interventions to address oncologist burnout, emotional well-being, or moral distress in the immediate period of the COVID-19 pandemic. Herein, the authors describe an ethical obligation to provide information and resources which oncologists require to fulfill their duty of providing high-quality oncology care. Considering the low supply of help (barely any governmental aid or additional psychological support for the healthcare workers), important lessons have to be learned to strengthen oncologists' mental health to sustain moral resilience and the ability to cope. These aspects should play a pivotal role in the workup of the COVID-19 pandemic and the preparation for future waves of infection.

The respondents to our survey estimated a mean financial loss of $21 \%$, ranging from 5 up to $50 \%$, for their institution for the fiscal year 2020, and a majority of $79 \%$ of respondents perceived a lack of support from the health insurance providers. While our results show that cancer treatments mostly were not affected by the pandemic, colleagues treating a larger proportion of general gynecologic patients may have expected a larger financial loss. It is also important to point out that reimbursement for treatment is done with a delay of two annual quarters in Germany and that the survey was conducted in times of great uncertainty. Therefore, the respondents may have overestimated the perceived financial loss at the time of the survey, and the actual financial impact of COVID-19 will have to be assessed in the future. 


\section{Conclusion}

Due to the rapid spread of the novel virus, healthcare systems worldwide had to adopt to the circumstances quickly. Evaluation of the experience within the first wave of the COVID-19 pandemic will help to prepare healthcare systems for further waves or future pandemics. Despite the described obstacles, German gynecologic oncologists were able to secure optimal outpatient cancer care. Nevertheless, the low prioritization of mental health or distress of the healthcare workers poses a serious threat to the maintenance of optimal treatment and patient care. In terms of preparation for future health crises or future waves of the pandemic, this should be discussed in the political discourse.

\section{Statement of Ethics}

The BNGO Board approved the voluntary survey (BNGO board meeting 05/2020). Informed consent to participate was not directly obtained but inferred by completion of the questionnaire.

\section{Conflict of Interest Statement}

The authors have no conflicts of interest to declare.

\section{Funding Sources}

No funding was received for this study.

\section{Author Contributions}

E. Vu and R. Förster designed the study. E. Vu, C. Schröder, J. Dülk, J. Vu, J.-J. Stelmes, and R. Förster collected the data. E. Vu, C. Schröder, J. Dülk, and R. Förster performed the statistical analyses and drafted the manuscript. E. Vu, C. Schröder, J. Dülk, J. Vu, J.-J. Stelmes, and R. Förster interpreted the results. J. Schilling and F.G. Förster critically revised the manuscript for important intellectual content. All authors read and approved the final manuscript.

\section{Data Availability Statement}

All data generated or analyzed during this study are included in this article or its online supplementary material. Further enquiries can be directed to the corresponding author.

\section{References}

1 Li Q, Guan X, Wu P, Wang X, Zhou L, Tong Y, et al. Early transmission dynamics in Wuhan, China, of novel coronavirus-infected pneumonia. N Engl J Med. 2020;382:1199-207.

2 Li R, Pei S, Chen B, Song Y, Zhang T, Yang W, et al. Substantial undocumented infection facilitates the rapid dissemination of novel coronavirus (SARS-CoV-2). Science. 2020; 368:489-93.

3 Marron JM, Joffe S, Jagsi R, Spence RA, Hlubocky FJ. Ethics and resource scarcity: ASCO recommendations for the oncology community during the COVID-19 pandemic. J Clin Oncol. 2020;38:2201-5.

4 Nakayama J, El-Nashar SA, Waggoner S, Traughber B, Kesterson J. Adjusting to the new reality: evaluation of early practice pattern adaptations to the COVID-19 pandemic. Gynecol Oncol. 2020;158:256-61

5 Pothuri B, Alvarez Secord A, Armstrong DK, Chan J, Fader AN, Huh W, et al. Anti-cancer therapy and clinical trial considerations for gynecologic oncology patients during the COVID-19 pandemic crisis. Gynecol Oncol. 2020;158:16-24.

6 Ramirez PT, Chiva L, Eriksson AGZ, Frumovitz M, Fagotti A, Gonzalez Martin A, et al. COVID-19 global pandemic: options for management of gynecologic cancers. Int J Gynecol Cancer. 2020;30:561-3.

7 Schrag D, Hershman DL, Basch E. Oncology practice during the COVID-19 pandemic. JAMA. 2020;323:2005-6.

8 Peiris JSM, Yuen KY, Osterhaus ADME, Stöhr K. Severe acute respiratory syndrome (SARS) in China and status of scientific and clinical knowledge, 14 April 2003. Wkly Epidemiol Rec. 2003;78:129-30.
9 Arabi YM, Balkhy HH, Hayden FG, Bouchama A, Luke T, Baillie JK, et al. Middle East respiratory syndrome. N Engl J Med. 2017; 376:584-94.

10 Petersen E, Koopmans M, Go U, Hamer DH, Petrosillo N, Castelli F, et al. Comparing SARS-CoV-2 with SARS-CoV and influenza pandemics. Lancet Infect Dis. 2020;20:e23844.

11 Jazieh AR, Akbulut H, Curigliano G, Rogado A, Alsharm AA, Razis ED, et al. Impact of the COVID-19 pandemic on cancer care: a global collaborative study. JCO Glob Oncol. 2020;6: 1428-38.

12 Monaghesh E, Hajizadeh A. The role of telehealth during COVID-19 outbreak: a systematic review based on current evidence. BMC Public Health. 2020;20:1193.

13 Spolverato G, Capelli G, Restivo A, Bao QR, Pucciarelli S, Pawlik TM, et al. The management of surgical patients during the coronavirus disease 2019 (COVID-19) pandemic. Surgery. 2020;168:4-10.

14 Nepogodiev D, Bhangu A, Glasbey JC, Li E, Omar OM, Simoes JF, et al. Mortality and pulmonary complications in patients undergoing surgery with perioperative SARS-CoV-2 infection: an international cohort study. Lancet. 2020;396:27-38.

15 Desai A, Sachdeva S, Parekh T, Desai R. COVID-19 and cancer: lessons from a pooled meta-analysis. JCO Glob Oncol. 2020;6:5579.

16 Downar J, Seccareccia D. Palliating a pandemic: "all patients must be cared for." J Pain Symptom Manage. 2010;39:291-5.

17 Dietz JR, Moran MS, Isakoff SJ, Kurtzman SH, Willey SC, Burstein HJ, et al. Recommen- dations for prioritization, treatment, and triage of breast cancer patients during the $\mathrm{CO}$ VID-19 pandemic. The COVID-19 Pandemic Breast Cancer Consortium. Breast Cancer Res Treat. 2020;181:487-97.

18 Ciavattini A, Delli Carpini G, Giannella L, Arbyn M, Kyrgiou M, Joura EA, et al. European Federation for Colposcopy (EFC) and European Society of Gynaecological Oncology (ESGO) joint considerations about human papillomavirus (HPV) vaccination, screening programs, colposcopy, and surgery during and after the COVID-19 pandemic. Int J Gynecol Cancer. 2020;30:1097-100.

19 Robert Koch-Institut. Berichts zum Krebsgeschehen in Deutschland 2016.

20 Callaway E, Ledford H, Viglione G, Watson T, Witze A. COVID and 2020: an extraordinary year for science. Nature. 2020;588(7839): $550-2$.

21 Das interne Strategiepapier der Innenministeriums zur Corona-Pandemie. Bundesministerium des Innern, für Bau uind Heimat. https:// www.bmi.bund.de/SharedDocs/downloads/ DE/veroeffentlichungen/2020/corona/szenarienpapier-covid19.html.

22 Corona: Krankenhäuser sollen ab Montag alle planbaren Eingriffe verschieben. Ärzteblatt Redaktion Corona. https://www.aerzteblatt. de/nachrichten/111034/Corona-Krankenhaeuser-sollen-ab-Montag-alle-planbarenEingriffe-verschieben.

23 Hasanzadeh M, Azad A, Farazestanian M, Mousavi Seresht L. COVID-19: What is the best approach in gynecological oncology patient management during the coronavirus pandemic? Asia Pac J Clin Oncol. 2021;17(4): 312-20. 
24 Mehta S, Machado F, Kwizera A, Papazian L, Moss M, Azoulay É, et al. COVID-19: a heavy toll on health-care workers. Lancet Respir Med. 2021;9(3):226-8.

25 Tang LV, Hu Y. Poor clinical outcomes for patients with cancer during the COVID-19 pandemic. Lancet Oncol. 2020;21:862-4.

26 Kutikov A, Weinberg DS, Edelman MJ, Horwitz EM, Uzzo RG, Fisher RI. A war on two fronts: cancer care in the time of COVID-19. Ann Intern Med. 2020;172:756-8.

27 Yang K, Sheng Y, Huang C, Jin Y, Xiong N, Jiang $\mathrm{K}$, et al. Clinical characteristics, outcomes, and risk factors for mortality in patients with cancer and COVID-19 in Hubei, China: a multicentre, retrospective, cohort study. Lancet Oncol. 2020;21:904-13.

28 Kuderer NM, Choueiri TK, Shah DP, Shyr Y, Rubinstein SM, Rivera DR, et al. Clinical impact of COVID-19 on patients with cancer (CCC19): a cohort study. Lancet. 2020;395: 1907-18.

29 Ueda M, Martins R, Hendrie PC, McDonnell T, Crews JR, Wong TL, et al. Managing cancer care during the COVID-19 pandemic: agility and collaboration toward a common goal. J Natl Compr Canc Netw. doi: 10.6004/ jnccn.2020.7560. Online ahead of print.

30 Jiang DM, Berlin A, Moody L, Kumar R, Hannon B, Krzyzanowska MK, et al. Transitioning to a new normal in the post-COVID era. Curr Oncol Rep. 2020;22:73.
31 Duffy SW, Tabár L, Yen AMF, Dean PB, Smith $\mathrm{RA}$, Jonsson $\mathrm{H}$, et al. Beneficial effect of consecutive screening mammography examinations on mortality from breast cancer: a prospective study. Radiology. 2021;299(3):541-7.

32 Toss A, Isca C, Venturelli M, Nasso C, Ficarra $\mathrm{G}$, Bellelli V, et al. Two-month stop in mammographic screening significantly impacts on breast cancer stage at diagnosis and upfront treatment in the COVID era. ESMO Open. 2021;6(2):100055.

33 Frey MK, Fowlkes RK, Badiner NM, Fishman D, Kanis M, Thomas C, et al. Gynecologic oncology care during the COVID-19 pandemic at three affiliated New York City hospitals. Gynecol Oncol. 2020;159:470-5.

34 Dinmohamed AG, Visser O, Verhoeven RHA, Louwman MWJ, van Nederveen FH, Willems SM, et al. Fewer cancer diagnoses during the COVID-19 epidemic in the Netherlands. Lancet Oncol. 2020;21:750-1.

35 Uwins C, Bhandoria GP, Shylasree TS, ButlerManuel S, Ellis P, Chatterjee J, et al. COVID-19 and gynecological cancer: a review of the published guidelines. Int J Gynecol Cancer. 2020;30:1424-33.

36 Shanafelt T, Ripp J, Trockel M. Understanding and addressing sources of anxiety among health care professionals during the COVID-19 pandemic. JAMA. 2020;323:2133-4.
37 Dewey C, Hingle S, Goelz E, Linzer M. Supporting clinicians during the COVID-19 pandemic. Ann Intern Med. 2020;172:752-3.

38 Skoda EM, Teufel M, Stang A, Jöckel KH, Junne F, Weismüller B, et al. Psychological burden of healthcare professionals in Germany during the acute phase of the COVID-19 pandemic: differences and similarities in the international context. J Public Health (Oxf). 2020;42:688-95.

39 Lai J, Ma S, Wang Y, Cai Z, Hu J, Wei N, et al. Factors associated with mental health outcomes among health care workers exposed to coronavirus disease 2019. JAMA Netw Open. 2020;3:e203976.

40 Wang C, Pan R, Wan X, Tan Y, Xu L, Ho CS, et al. Immediate psychological responses and associated factors during the initial stage of the 2019 coronavirus disease (COVID-19) epidemic among the general population in China. Int J Environ Res Public Health. 2020; 17:1729.

41 Hlubocky FJ, Symington BE, McFarland DC, Gallagher CM, Dragnev KH, Burke JM, et al. Impact of the COVID-19 pandemic on oncologist burnout, emotional well-being, and moral distress: considerations for the cancer organization's response for readiness, mitigation, and resilience. JCO Oncol Pract. 2021; 17(7):365-74. 